Papers and procedings of the Royal Society of Tasmania, Volume 107

\title{
STRUCTURAL PETROLOGY OF THE DAVEY RIVER AREA, SOUTHWESTERN TASMANIA
}

\author{
by C.J. Maclean \\ Minerals Dept., Esso Aust. Ltd., Sydney \\ (with one text figure and one plate)
}

\section{ABSTRACT}

Standard techniques of microtextural analysis have been applied to the Precambrian rocks of the Davey River area. It is concluded that $t$ wo periods of deformation and attendant recrystalisation during lower precambrian time produced garnet grade and later biotite grade assemblages.

\section{INTRODUCTION AND ACKNOWLEDGMENTS}

This work is an application of the logical criteria developed by H.J. Zwart (1960 and 1962) and A.H. Spry (1969b) for determining the time relationship of crystallisation to deformation for minerals in a netamorphic assemblage. Several other workers have used these techniques on other Tasmanian areas (Gee 1963; Spry 1963, $1969 \mathrm{a}, 1969 \mathrm{~b}$ ) and this article attempts to place the rocks of Port Davey into the established history of metamorphic and structural events.

The help of Dr. R. Vernon in applying this technique is gratefully acknowledged; though all consequences arising from the validity of the method and all responsibility for inferences made, are the author's own.

\section{REGIONAL GEOLOGY}

The Precambrian rocks of the Davey River area are part of the southwestern porion of the central, older metamorphic basement of Tasmania (the Tyennan Nucleus).

The rocks consist of metamorphosed and deformed quartzites and schists which strike north-northeast and are generally steeply dipping. These Precambrian and overlying Palaeozoic rocks have been mapped in greater detail $(1: 25,000)$ by Maclean and Bowen (1971). The quartzites have formed ridges separating plains derived from deep in situ weathering of the schists.

\section{LITHOLOGY}

Quartzites

Two types of quartzite have been distinguished. A well-layered, slabby quartzite and a schistose quartzite. The major quartzite belts are largely composed of the slabby quartzite, with the schistose quartzite becoming more common on the edge of these belts, and within the pelites.

The slabby quartzite occurs as long regular slabs 5 to $20 \mathrm{~cm}$ thick separated by planes of partings. These planes are often parallel to internal colour laminations, defined by differences in amounts of mica and/or differences in quartz-grain size. The etching of grain boundaries on weathered surfaces creates a delicate record of even the weakest deformation.

The schistose quartzite is an impure quartzite, containing varying amounts of albite, muscovite and haematite. The haematite is crystalline and may grow in crystals as large as $2 \mathrm{~mm}$. No garnets were encountered in the quartzites. 

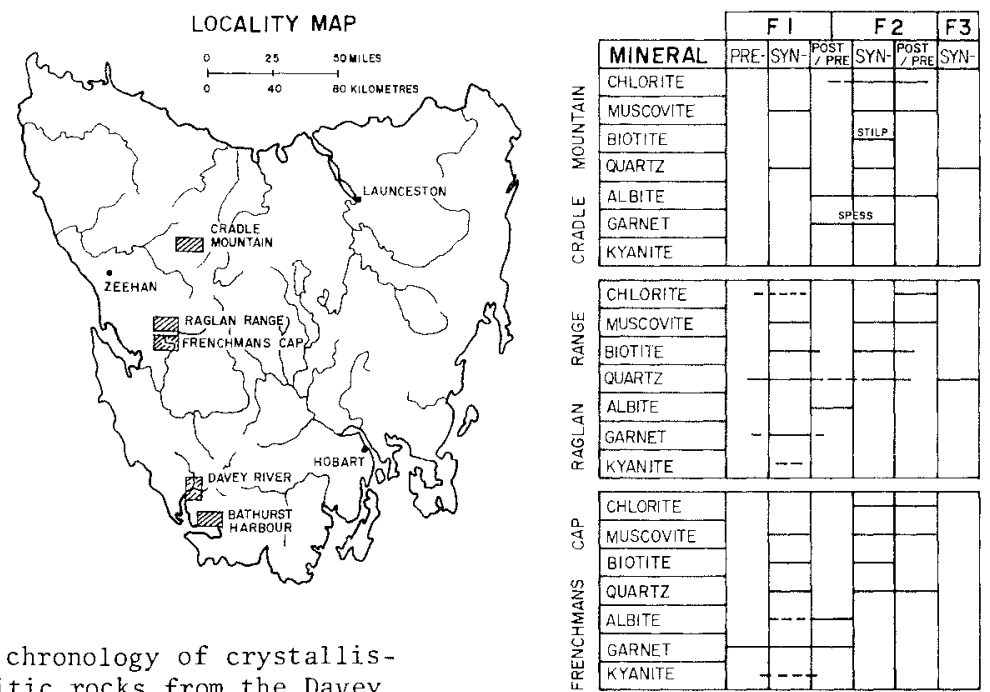

FIG. 1 - The chronology of crystallisation in pelitic rocks from the Davey River area is compared with that from other areas in Tasmania. Information for the figure was derived from the work of: Gee, Marshal \& Burns, 1970 (Cradle Mountain); Gee, 1963 (Raglan Range); Spry, 1963 (Frenchman's Cap); \& Spry \& Baker, 1965 (Bathurst Harbour). The location of these areas is also shown.

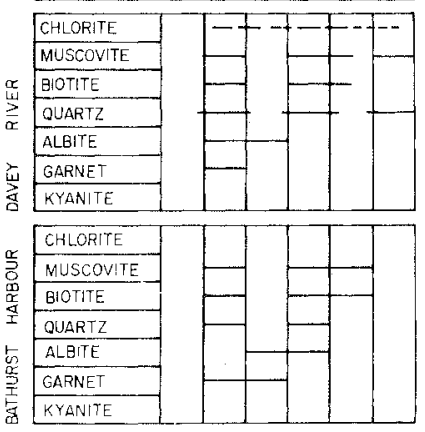

Schists

The schists are fine to medium-grained quartz-muscovite schists, with albite and opaque materials, and more rarely with biotite and garnet. The quartz forms lenticles several grain diameters wide, paralle1 to the dominant foliation. These lenticles are separated by bundles of wavy muscovite. This muscovite is in places quite opaque due to an abundance of dusty opaque inclusions, probably graphite, which are discussed below.

The major lithological boundaries of quartzite and schist probably represent original sedimentary layering. Small scale boundaries, however, are commonly folded, with interdigitations of rock types, probably representing transposition-foliation. No carbonates or meta-igneous rocks were encountered in the area, though Spry (1969a) described amphibolites from the adjacent area to the south.

\section{TEXTURAL SEQUENCE}

The Tasmanian basement is accepted as having suffered three episodes of deform- 
ation which generated three recognisably distinct foliations. These three interacting foliations are also recognised at Port Davey (plate 1a, 1b).

S1. The earliest recognised foliation is a transposition surface sub-parallel to bedding. Mesoscopically this dissected the bedding into long discontinuous intraformational lenses. Microscopically, it can be identified by a colour banding, which is due to variations in grain size and quantity of quartz and muscovite. Several lineations were produced during the deformation that produced S1. Textural expressions include micro-crenulations in schists and surface rodding and colour streaking in quartzites.

S2. In places $\mathrm{S} 1$ is almost obliterated by a strong crenulation cleavage (Rickard 1961) producing alternating layers of muscovite-rich and quartz-rich folia. In comparison with other areas of the State this foliation is only locally developed, so that the dominant structure in most outcrops is S1, or rarely so (bedding). In areas where S2 does not develop as an axial surface foliation at a1l, the folds show an erratic, wavy axial surface. Lineations of this age are expressed as a surface rodding in quartzites, as axes of chevron folds and as crenulations in schists.

S3. A weak foliation is seen to cross S1 and S2. at high angles in some places. In the schists it is irregular, weakly crenulates existing micas, and bends lithological folia. The crenulations are from 0.1 to $1 \mathrm{~mm}$ wide in the schists and in quartzites, its trace forms anastomosing lines spaced 1.0 to $3.0 \mathrm{~mm}$ apart which, as a whole, parallel a mica foliation.

\section{PETROLOGY}

Quartz grains, $0.2 \mathrm{~mm}$ long are dimensionally elongated parallel to the dominant foliation (S1, S2 or S3) in any specimen. Where mica is abundant, quartz grains tend to be smaller and more elongated (plate $1 \mathrm{c}$ ). This is presumably due to restriction of quartz grain growth in one or more directions (Vernon 1968) by mica flakes. Quartzquartz grain boundaries are usually sutured, but in some sections are polygonal, suggesting some stress-free boundary adjustment.

Petrofabric diagrams of the quartzites (prepared by Nisbet 1970) show that the c-axes of quartz grains define a cleft girdle pattern, with maxima lying at right angles to the foliation (S1). It is suggested (from the work of wilson 1970 and Nisbet 1970) that this pattern might be related to that period of grain growth where newly nucleated grains grew and began to adjust boundaries with recrystallised detrital grains. The crystallographic orientation and dimensional elongation of quartz grains is most probably due to crystallation being syntectonic with S1, S2 and S3.

In the schists muscovite occurs as small, twisted flakes forming long wavy shreds parallel to each foliation. These wisps are generally small $(0.05 \mathrm{~mm})$ but reach lengths of up to $0.6 \mathrm{~mm}$ where abundant. Smaller flakes are usually ragged, stained with iron oxide, and contain many tiny opaque inclusions. In places they are so abundant that the muscovite shreds appear opaque, imparting a dark grey colour to the hand specimen. Gee has reported similar muscovite at Cradle Mountain (1968) and the Raglan Range (1963), the colour being due to graphitic inclusions. Muscovite also occurs as small inclusions in albite. In quartzites, the muscovite occurs as straight and sometimes needle like crystals (in section) $0.1 \mathrm{~mm}$ long, which may be clear or stained with iron oxides.

Crenulated muscovite is of two types: interlocking grains which are bent and have strained extinction, and therefore probably predate the formation of 52 , and unbent grains which have decussate boundaries and sharp extinction. This second type is most probably due to mimetic growth after the formation of $\mathrm{S} 2$. Although three generations of muscovite have been recognised on the basis of deformation by later foliations it has not been possible to distinguish them optically. Nevertheless the 


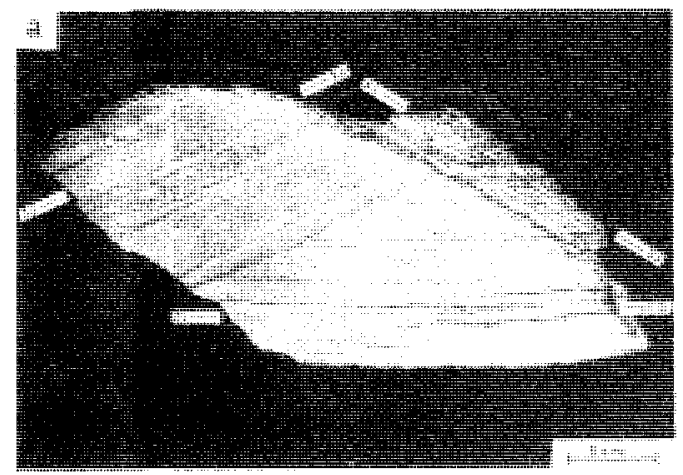

a. A horizontal slice of vertically foliated quartzite showing the crenulation of $S 1$ by $S 2$ and the latex superposition of $\mathrm{S} 3$ on both. The development of $\mathrm{S} 2$ is usually local and intense as shown. The section is 2 mm thick and is illuminated with ordinary light from the rear. (Specimen 1630, lacquarie University collection).

b. Inlarged central portion of "a" showing the lenticular lithological foliae developed by $\mathrm{S} 2$.
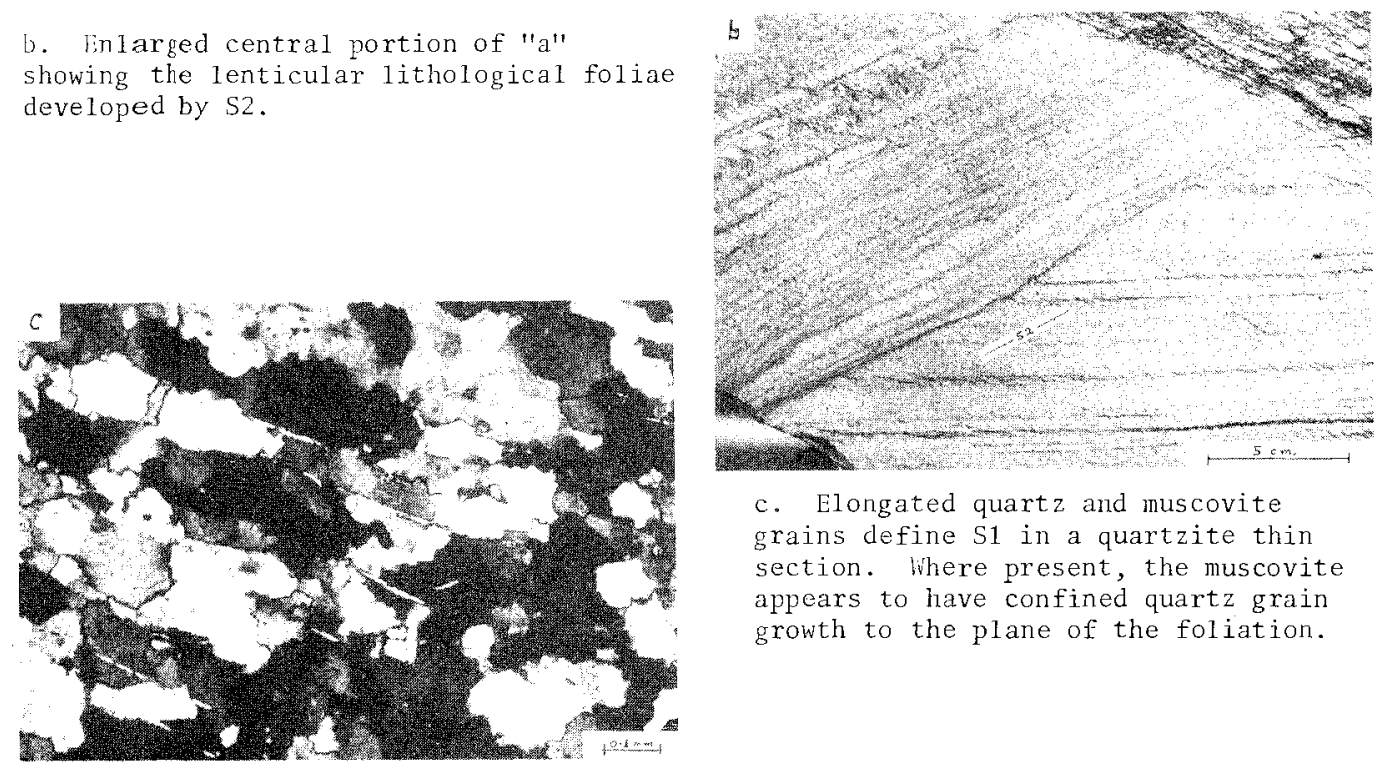

c. Elongated quartz and muscovite grains define 51 in a quartzite thin section. Where present, the muscovite appears to have confined quartz grain growth to the plane of the foliation.

d. The development of S2 in an albite schist. A foliated background of quartz and mica (S2) envelops lozenge-shaped albite porphyroblasts, with S1 preserved as an internal foliation (Si) defined by inclusions. $5 \mathrm{i}$ is planar, discordant with Se, and generally parallel to $\mathrm{Si}$ in other porphyroblasts.

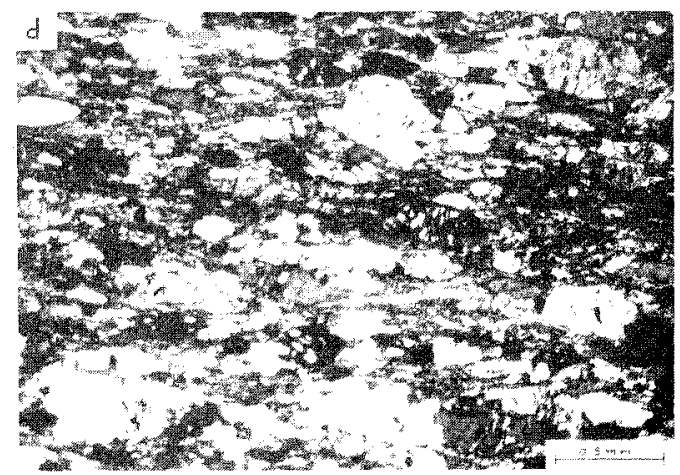


presence of deformed muscovite grains suggests that muscovite growth was pre-tectonic to $\mathrm{S} 2$, and later, to S3.

Biotite is scarce in all specimens, as is reported from other parts of the State. Where present it is intimately intergrown with $S 1$ and $\$ 2$ muscovite, and attains similar dimensions, suggesting synchronous crystallisation. As with muscovite, two types of crenulated biotite are present: bent, strained wisps (presumably pre-S2) and straight, lecussate grains (presumably post-S2). Both types are pleochroic from dark brown to pale olive brown.

Chlorite occurs as porphyroblasts $(0.4 \mathrm{~mm})$ wrapped by the $\mathrm{S} 2$ foliation, and orjentated at all angles to $\mathrm{S2}$, suggesting that this generation of chlorite was pretectonic to S2. As they are large single grains it is unlikely that they have formed as a replacement of garnet, in which case an aggregate would be expected (see below). They show anomalous blue interference colours, are pleochroic in yellow (X) and pale green ( $Y$ and $Z$ ) extinguish parallel to cleavage traces and are optically negative with a $2 \mathrm{~V}$ of $10^{\circ}$. They are therefore probably penninite (Winchell and Winchell, 1964). very rarely, these porphyroblasts enclose discordant graphitic trails.

Chlorite is also present as a replacement of garnet, occurring as clusters of sma11, randomly orientated grains in and around garnet porphyroblasts. They are pleochroic in yellow-brown and olive-brown, and have low birefringence. The same variety of chlorite occurs along the S2 and crenulated S1 foliations, formed presumably during the formation of 52 , though this is in doubt since the possibility of mimetic growth cannot be discounted. Late stage vein-chlorite of a different type (extremely low birefringence) is seen to cross S1, S2 and S3 foliations.

In the coarser grained schists, albite occurs as lozenge shaped. porphyroblasts, $0.6 \mathrm{~mm}$ long. These porphyroblasts show sharp extinction and are locally simply twinned They invariably have abundant rounded inclusions of garnet, quartz, muscovite and opaque grains, as well as minute opaque inclusions which fom sigmoidal lines within the grains. These "dusty" trails have the same appearance as those seen in the mica grains enclosing porphyroblasts, which suggests that the growing albite grain was able to expel other material by diffusion but not the opaque trails. Consequently, they remain as relics of the earlier foliation.

In comparison with these porphyroblasts of albite, thin sections in which $\mathrm{S} 2$ is absent and $\mathrm{S} 1$ is present show abundant small albite grains of similar dimensions to the neighbouring quartz grains. They are slightly elongated parallel to the mica flakes defining S1, suggesting that some of the crystallisation of albite took place during the formation of $\mathrm{S} 1$. Inclusions of other minerals are usually planar within an albite porphyroblast, are discordant with respect to the enveloping foliation (S2), and have a parallel alignment with other porphyroblasts. This suggests a pre-S2 origin The inclusion of an earlier foliation (a tectonic, rather than a sedimentary one) suggests that they are post-tectonic, or syn-tectonic with respect to $s 1$ (plate $1 \mathrm{~d}$ ).

In thin sections where S2 is absent and S1 scarcely discernible, abundant tiny equant albite grains can be seen amongst the quartz grains. The presence of such grains suggests that the albite was an original constituent of the rock and need not have been introduced metasomatically after the onset of metamorphism, as has been considered as a possibility by other workers, notably Spry (1963) and Gee (1963). The albite may have nucleated at the same time as the rest of the assemblage, uut selected grains grew to porphyroblastic size, at the expense of others after the rest of the assemblage had ceased growing. This supports the chemical evidence of Spry (1963) and Gee (1963) which also obviates soda metasomatism. These albite grains commonly possess ragged deformation twins.

Small garnet porphyroblasts $(0.2 \mathrm{~mm})$ are wrapped by the $\mathrm{S} 2$ foliation and are probably pre-tectonic to it. They are extensively altered to chlorite. The large porphyroblasts with relict $\mathrm{S} 1$ inclusions described from other areas are not observed 
at Port lavey.

These observations are summarised by Figure 1, which relates crystallisation to deformation.

\section{REGIONAL SIGNIFICANCE}

The first metamorphic event produced the assemblage quartz-muscovite-chloritebiotite-garnet-albite, and the second stage produced quartz-albite-muscovite-chloritebiotite, leaving relics of the first-stage assemblage. In tems of the facies classification of Turner and Verhoogen (1960) these rocks belong to the Greenschist Facies of regional metamorphism.

The observation of stilpnomelane, almandine and kyanite in other parts of the Tyennan Nucleus suggests that the region belongs to the Barrovian type facies series. It may therefore be inferred from the previous section that at the Davey River F1 reached garnet grade and F2 reached biotite grade. These events are attributed to the Frenchman Orogeny whereas F3 is assumed to be of Tabberabberan age.

The remarkably similar character of foliations and metamorphism from other Precambrian areas in Tasmania allows them to be compared in general terms as shown by Figure 1. It has been inferred that M1 closely followed S1, with a period of albite growth separating this episode from a less intense, synchronous M2/S2 episode. This was followed much later by S3. It is proposed that the area just south of Frenchman's Cap represents a metamorphic high, the grade diminishing to the north and south.

\section{REFERENCES}

Bowen, E.A. and Maclean, C.J., 1971: Palaeozoic Rocks of the Davey River South West Tasmania. Pap. Proc. R. Soc. Tasm., 105, 21-28.

Gee, R.D., 1963: Structure and Petrology of the Raglan Range, Tasmania. Buzz. Geoz. Surv. Tasm., 47.

, Marsha11, B. and Burns, K.L., 1970: The Metamorphic and Structural Sequence in the Precambrian of the Cradle Mountain Area, Tasmania. Tasm. Dept. Mines, Geol. Survey Report No. 11.

Maclean, C.J. and Bowen, E.A., 1971: Structure of the Precambrian Rocks of the Davey River Area, South-Western Tasmania. Pap. Proc. R. Soc. Tasm., 105, 97-104.

Nisbett, B.W., 1970: Unpublished report for honours Thesis, Aust. Nat. Univ.

Rickard, M.J., 1961: A Note on Cleavages in crenulated Rocks. Geol. Mag., 98.

Spry, A.H., 1963: Precambrian Rocks of Tasmania, Part V - Petrology and Structure of the Frenchman's Cap Area. Pop. Proc. R. Soe. Tasm., 97, 105-128.

, 1969a: Notes on some rocks in the Port Davey area. Unpublished report for the Tasmanian Hydro Electric Commission.

, 1969b: Metomorphic Textures. Pergamon Press.

and Baker, W.E., 1965: The Precambrian rocks of Tasmania, Part VII.

Pap. Proc. R. Soc. Tasm., 99, 17-26.

Turner, F.J. and Verhoogen, J., 1960: Igneous and Metamorphic Petrology. McGraw Hi11, New York. 
Vemon, R.H., 1968: Microstructure of high grade Metamorphie looks at Broken Hil1, Australia. J. Fetrol, , $1-22$.

Wilson, C.J., 1970: Whe microfabric of a defomed quartzite sequence, Mt. Isa, Queensland. aust. Nat. Univ. Th. D. Thesis, mpublished.

irinchel1, A.N. and WincheI1, 11., 1904: Elements of optical Mineratogy, in introduction to Mieroscopie Petrography. John Wiley 8 Sons, wew Xork.

Ewart, 1... ., 1960: The chronologica] Succession of Folding and Motanorphism in the central Pyrenees. Sonderdruck aus der Geotogisonen fumdechau, Band 50.

1962: On the betermination of Polymetamorobic lineral Associations, and its Application to the Bozost Arca (Contral pyrenees). Sonderstruek aus der Geotogischen Rundschan, Band 50, 38-65. 